\title{
Platinum Pyrimidine Blues: Still a Challenge to Bioinorganic Chemists and a Treasure for Coordination Chemists
}

\author{
Bernhard Lippert ${ }^{\star}$
}

\begin{abstract}
A class of intensely colored platinum complexes, derived from the hydrolysis product of the antitumor agent cisplatin, cis-[ $\left.\mathrm{Pt}\left(\mathrm{NH}_{3}\right)_{2}\left(\mathrm{H}_{2} \mathrm{O}\right)_{2}\right]^{2+}$, and pyrimidine nucleobases (pym) and related cyclic or open amides, and generally termed 'Platinum Blues', is discussed. First reported over 30 years ago, major questions concerning their nature have been solved since then, for example their mixed valency and paramagnetism. Their modes of action as antitumor agents and as nucleic acid stains remain elusive, however. It has generally been assumed that the 'Blues' adopt linear chain structures, thus permitting short Pt•••Pt contacts, but more recent findings demonstrate that these ligands also allow cyclic structures to be formed (metallacalix[n]arenes). They provide a wealth of interesting properties with regard to host-guest chemistry and non-covalent DNA binding. These developments are reviewed.
\end{abstract}

Keywords: DNA interactions · Non-covalent binding · Platinum Pyrimidine Blues

\section{Introduction}

Cisplatin (cis-diamminedichloroplatinum(II) or according to an IUPAC recommendation from 2006: cis-diamminedichloridoplatinum(II)) has been the first metal-containing drug widely applied in cancer chemotherapy.[1] Once termed as the 'penicillin of cancer drugs' because of its effectiveness as first line agent in the treatment of cancers of the testes, ovaries, bladder, and lung, its clinical success is remarkable. With its second generation relatives carboplatin (cis-diammine(1,1-cyclobutanedicarboxylato)platinum(II)) and oxaliplatin $((1 R, 2 R$-diaminocyclohexane $)$ oxalatoplatinum(II)) now likewise in clinical use, Pt drugs have reached blockbuster status in cancer chemotherapy, with annual
${ }^{\star}$ Correspondence: Prof. Dr. B. Lippert

Fachbereich Chemie

Universität Dortmund

D-44221 Dortmund, Germany

Tel.: +492317553840

Fax: +49 2317553797

E-Mail: bernhard.lippert@uni-dortmund.de sales figures of around 2-3 billion US \$. The astonishing simplicity of cisplatin an achiral molecule composed of eleven atoms only - contrasts the complexity of most synthetic organic antitumor drugs or natural products such as taxol.

There have been numerous attempts over the years to potentiate the effect of $\mathrm{Pt}$ antitumor drugs by putting together two or more Pt entities in a single molecule. Despite encouraging initial testing data on compounds developed by Farrell and Spinelli, ${ }^{[2]}$ no such compound is yet approved by federal health agencies.

The story of the 'Platinum Pyrimidine Blues', a class of oligonuclear metal complexes discovered in Rosenberg's laboratory in the $1970 \mathrm{~s},{ }^{[3]}$ and considered at the time promising second-generation $\mathrm{Pt}$ drugs, is no success story either as far as its medicinal performance is concerned, but its exciting chemistry has kept them alive. As it looks, interest in them will continue at least for a while, and the 'Blues' in fact may come full circle, albeit in a way different from what they initially were meant for.

\section{A Brief History of the 'Pt Pyrimidine Blues'}

It was in the aftermath of the discovery of cisplatin, when its reactivity patterns with nucleic acids were still largely unclear and when reactions with the components of nucleic acids were carried out in order to obtain a deeper understanding of its chemistry, that in the Rosenberg lab Raman-spectroscopic studies on the interactions of the diaqua species of cisplatin with polyU (U $=$ uridine) were carried out. ${ }^{[4]}$ The observation of an intense blue color formed during this reaction, and subsequent findings of similar behaviors of the parent nucleobase uracil as well as related pyrimidine ligands (thymine, cytosine) and numerous other amides, presented a challenge to coordination chemists. Two more findings, namely the remarkable antitumor activity of these 'Blues' against Sarkoma S180 bearing mice ${ }^{[3]}$ and the propensity of the 'Blues' to stain nucleic acids in cells ${ }^{[5]}$ endowed them with considerable prominence among chemists, biologists, and pharmacologists by the mid 1970s. Although at one point even introduced into clinical use, the use of the 'Pt Pyrimidine Blues' was eventually discontinued due to problems with their reproducible synthesis and their incomplete characterization.

\section{Composition and Physico-Chemical Properties}

It soon became evident that the 'Pt Pyrimidine Blues' were relatives of so-called 'Platinblau' materials obtained by Hof- 
mann in Munich (Germany) in 1908 during hydrolysis of Pt-bonded acetonitrile to acetamidate ligands. Even earlier, in 1895, the famous Russian platinum chemist Kurnakow had mentioned the formation of blue and purple products when reacting $\mathrm{K}_{2} \mathrm{PtCl}_{4}$ with acetamide. Pioneering work by Krogmann and others on intensely colored $\mathrm{Pt}$ chain compounds in the 1960 s contributed to our understanding of the 'Blues' being mixed-valence Pt compounds, as confirmed by EPR spectroscopy. ${ }^{[6]}$ By then it was also clear that the 'Pt Pyrimidine Blues' were oligomeric, cationic species, requiring anions for charge neutralization. ${ }^{[6]}$ The average oxidation state of $\mathrm{Pt}$ was rather variable and only fractionally greater than 2.0 in most cases.

\section{The Dimer-of-Dimer Motif and its Extension}

The X-ray crystal structure determination of a 'Pt $\alpha$-Pyridone Blue' reported from Lippard's lab in 1977 was a milestone in 'Pt Blues' chemistry in that it revealed a structural motif of the 'Blues', namely the dimer-of-dimer stacking principle.[7] According to it, two dinuclear cis- $\left[\left\{\mathrm{Pt}\left(\mathrm{NH}_{3}\right)_{2}\right\}_{2}(\mathrm{~L}-\mathrm{N}, \mathrm{O})_{2}\right]^{2+}$ species $(\mathrm{L}=$ bridging ligand, here: $\alpha$-pyridonate anion) with head-head arrangement of the two ligands L, stack on top of each other, held together by hydrogen bonds between $\mathrm{NH}_{3}$ ligands and $\mathrm{O}$ groups of ligands $\mathrm{L}$ and by metal-metal bond formation (Fig. 1). The four Pt atoms have undergone partial oxidation (removal of one electron out of four $\mathrm{Pt}(\mathrm{II})$ ) to produce a $\mathrm{Pt}_{4}$ chain with an average oxidation state of 2.25 per metal entity. The very same motif was subsequently also shown to hold up for the pyrimidine model nucleobase 1-methyluracil, with bridging of metals via $\mathrm{N}(3)$ (deprotonated) and $\mathrm{O}(4){ }^{[8]}$

In a series of articles, Matsumoto and Sakai then demonstrated that it is possible to build up longer stacks of dinuclear Pt complexes containing bridging aliphatic amidate ligands and to partially oxidize them. ${ }^{[9]}$ Work by Sakai et al. further elaborated on this theme, albeit applying different systems. ${ }^{[10]}$

The major difference between these longer Pt chain compounds on one hand, and the 'Blues' derived from Rosenberg's pyrimidine ligands on the other, is that with the latter it is impossible for steric reasons to extend the stacking of head-head dimers beyond the dimer-of-dimer level. The presence of a second exocyclic group in ortho position to the $\mathrm{N}(3)$ site simply prevents such a possibility. This is also true for the $\alpha$-pyridone $[\operatorname{Pt}(2.25)]_{4}$ complex, despite the fact that there is only a proton $(\mathrm{H}(6))$ adjacent to the ring $\mathrm{N}$ atom $(\mathrm{N}(1))$ rather than an oxygen atom of a carbonyl

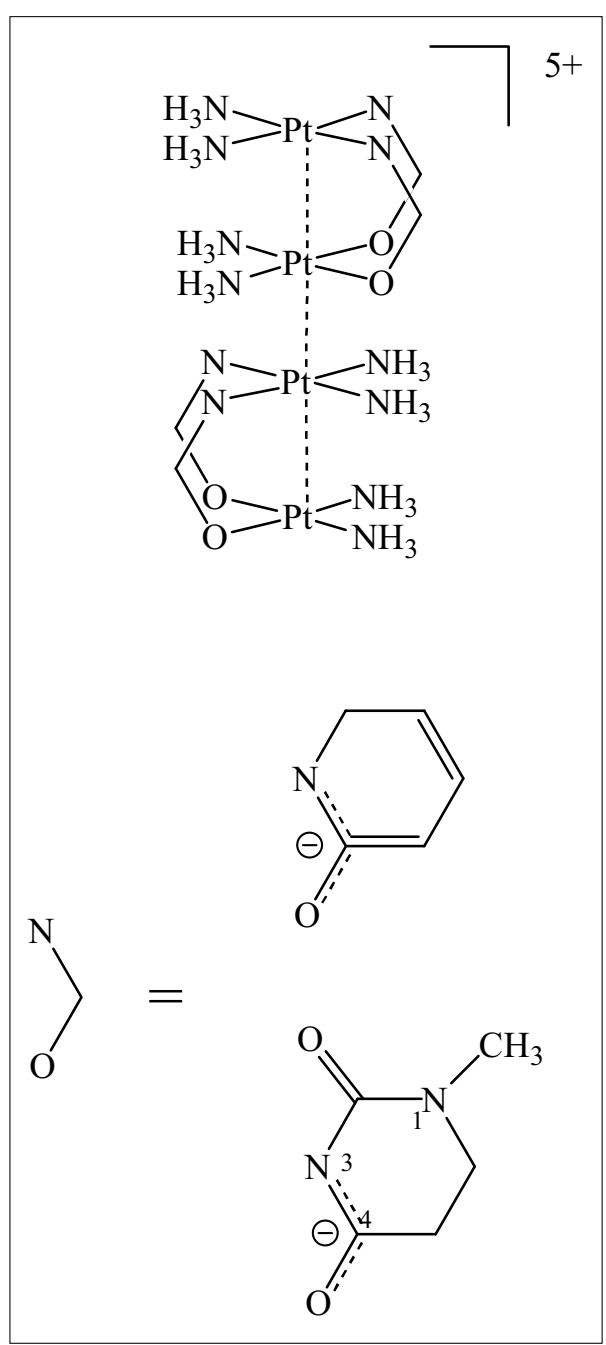

Fig. 1.

group as with 1-methyluracilate. The view that 'Pt Pyrimidine Blues' owe their properties exclusively to the 'dimer-of-dimer' motif is, however, inconsistent with numerous experimental observations which suggested a higher aggregation state of the 'Pt Pyrimidine Blues'. A major impetus of the research carried out by my own group in the 1980s and 1990s has, therefore, been the attempt to find motifs that provided a rationale for larger oligomeric species from smaller building blocks by applying metal ions other than $\mathrm{Pt}^{[4,11]}$ Among others, Pd ions were applied (see also below).

\section{Cyclic Structures as an Alternative: $\mathbf{N}, \mathbf{N}-B r i d g i n g$}

Our finding that the simple 1:1 complex of (en)Pt $\mathrm{Pt}^{\mathrm{II}}$ with uracil, [(en)Pt(HU$\left.\mathrm{N} 1)\left(\mathrm{H}_{2} \mathrm{O}\right)\right]^{+}(\mathrm{en}=$ ethylenediamine; $\mathrm{HU}$ $=$ uracil monoanion) spontaneously selfassembles to a cyclic tetramer $\{[(\mathrm{en})$ $\left.\mathrm{Pt}(\mathrm{HU}-\mathrm{N} 1, \mathrm{~N} 3)]_{4}\right\}^{4+}$ has provided a major new aspect regarding possible structures of 'Blues' derived from the parent pyrimidine nucleobases. ${ }^{[12,13]}$ Here was a tetranuclear Pt complex described which did not display the $\mathrm{N}$ (endocyclic), $\mathrm{O}$ (exocyclic) binding pattern, but rather a twofold N,N (endocyclic) one. The uracil ligand was nevertheless monoanionic only, because a proton had moved to an exocyclic oxygen atom to generate a rare uracilate tautomer (Fig. 2). Moreover, 'double-decker' constructs with four additional metal ions bonded to the exocyclic oxygen atoms of the uracilate ligands (now dianionic) could be prepared, e.g. $\left[\left\{\text { cis }-\left(\mathrm{NH}_{3}\right)_{2} \mathrm{Pt}_{4}\right\}\{(\mathrm{en}) \mathrm{Pt}\}_{4} \mathrm{U}_{4}\right]^{8+}(\mathrm{U}=$ uracil dianion), ${ }^{[14]}$ which then also involved the exocyclic oxygen atoms as metal binding sites.

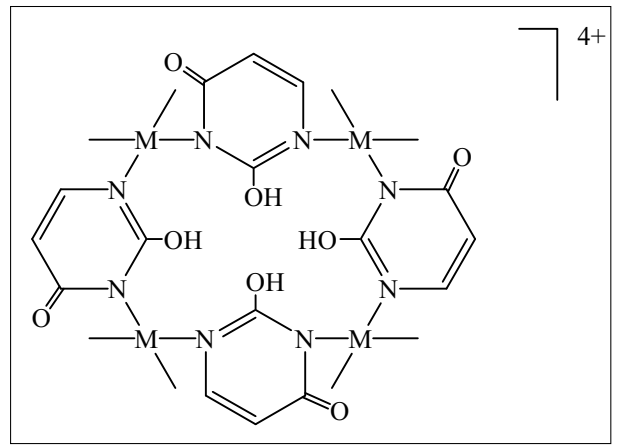

Fig. 2.

The dynamic behavior of the cyclic tetramer and its similarity with calix[4] arenes led us to propose this compound to be termed a metallacalix[4]arene. Indeed, it was found that the metallacalix[4]arenes adopted both 1,3-alternate and cone conformations. It was subsequently demonstrated that 2-hydroxypyrimidines and a series of substituted derivatives likewise formed discrete metallacalix[n]arenes, with $\mathrm{n}=3,4$, and 6.[15] If $C_{2 v}$-symmetric, the two ring-nitrogen atoms of the ligand become equivalent, which clearly facilitated the self-assembly processes of their formation. A major point of interest in these compounds was their propensity to act as hosts for anions (when present as cone conformers) and even for cations such as $\left[\mathrm{Cu}\left(\mathrm{H}_{2} \mathrm{O}\right)_{6}\right]^{2+} \cdot{ }^{[16]}$ While the former was not surprising, considering the positive charge of the metallacalix[4]arene, the latter was. Its realization is a consequence of the basic properties of the exocyclic oxygen atoms of the deprotonated pyrimidine (pym) ligands and their ability to either coordinate metal ions directly (see above) or to bind metal-aqua complexes in an outer-sphere fashion via hydrogen bonds. In principle, similar weak association patterns could be realized between cationic building blocks of 'Pt Pyrimidine Blues'.

\section{$\mathbf{N}, \mathbf{N}-$ Bridging in Mixed Pt,Pd Complexes}

In order to bypass the inherent problem of the slow reaction kinetics of Pt chemis- 
try, we have occasionally resorted to $\mathrm{Pd}^{\mathrm{II}}$ as a structural mimic of $\mathrm{Pt}^{\mathrm{II}}$. For example, by combining Pt-pym building blocks, e.g. cis- $\mathrm{Pt}\left(\mathrm{NH}_{3}\right)_{2}(1-\mathrm{MeU})_{2}$ (1-MeU = 1-methyluracil anion), with $\left[(\text { en }) \mathrm{Pd}\left(\mathrm{H}_{2} \mathrm{O}\right)_{2}\right]^{2+}$ or $\left[\mathrm{Pd}\left(\mathrm{H}_{2} \mathrm{O}\right)_{4}\right]^{2+}$, we have prepared and characterized di- and trinuclear mixed-metal $(\mathrm{Pt}, \mathrm{Pd} ; \mathrm{Pt}, \mathrm{Pd}, \mathrm{Pt})$ complexes that yielded structural models of the corresponding $\mathrm{Pt}_{2}$ and $\mathrm{Pt}_{3}$ compounds and, in the case of the PtPdPt compound, even provided mixedvalence state species. ${ }^{[17]}$ In these compounds $\mathrm{Pd}^{\mathrm{II}}$ is necessarily bonded to exocyclic oxygen atoms of the pym ligands, as the N(1) position is blocked by a methyl group and unavailable for metal coordination.

We have recently extended this concept also to Pt complexes of unsubstituted uracil[18] as well as mixed uracil, cytosine compounds. ${ }^{[19]}$ In both cases the cis-a ${ }_{2} \mathrm{PtI}^{\mathrm{II}}$ $\left(\mathrm{a}=\mathrm{NH}_{3}\right.$ or $\left.\mathrm{a}_{2}=\mathrm{en}\right)$ entity was bonded to endocyclic nitrogen atoms of the pym base (N(1) of uracil and $\mathrm{N}(3)$ of cytosine, respectively) to give $c i s-\mathrm{Pt}\left(\mathrm{NH}_{3}\right)_{2}(\mathrm{HU}-\mathrm{Nl})_{2}$ and $[\mathrm{Pt}(\mathrm{en})(\mathrm{HU}-\mathrm{N} 1)(\mathrm{HC}-\mathrm{N} 3)]^{+}$. These compounds were subsequently allowed to react with $\mathrm{Pd}(\mathrm{en})(\mathrm{OH})_{2}$ and $\mathrm{Pd}\left(2,2^{\prime}\right.$-bpy $)(\mathrm{OH})_{2}$, respectively. The compounds observed in solution and in a number of cases isolated and characterized by X-ray crystal structure analysis were of the following metal stoichiometries: $\mathrm{Pt}_{2} \mathrm{Pd}, \mathrm{Pt}_{2} \mathrm{Pd}_{2}, \mathrm{Pt}_{2} \mathrm{Pd}_{3}, \mathrm{Pt}_{2} \mathrm{Pd}_{4}$, $\mathrm{Pt}_{4} \mathrm{Pd}_{4}, \mathrm{Pt}_{2} \mathrm{Pd}_{6}$, and $\mathrm{Pt}_{4} \mathrm{Pd}_{10}$. With the exception of the first complex $\left(\mathrm{Pt}_{2} \mathrm{Pd}\right)$, all the other examples are cyclic compounds. In all cases Pd is bonded to at least one endocyclic nitrogen atom of a pym nucleobase, but in addition, binding to exocyclic groups of uracil $(\mathrm{O}(4))$ and/or cytosine $(\mathrm{O}(2)$; $\mathrm{N}(4))$ is realized as well. As a consequence short contacts ( $3 \AA$ or less) between metals $(\mathrm{Pt} \bullet \bullet P d ; \mathrm{Pd} \bullet \bullet \bullet \mathrm{Pd})$ are possible, with the metals adopting head-tail or head-head arrangements. In Fig. 3 a representative example of a cyclic mixed metal complex comprising four (en) $\mathrm{Pt}^{\mathrm{II}}$ and ten (en) $\mathrm{Pd}^{\mathrm{II}}$ as well as eight uracil dianons is shown. It was obtained upon reaction of $c$ is $-\mathrm{Pt}\left(\mathrm{NH}_{3}\right)_{2}(\mathrm{UH}-$ $\mathrm{Nl})_{2}$ with $\mathrm{Pt}(\mathrm{en})(\mathrm{OH})_{2} \cdot{ }^{[18]}$ As can be seen, the cation of +12 charge displays a multitude of different coordination patterns such as $\mathrm{Pt}(\mathrm{U}-\mathrm{Nl})_{2}, \mathrm{Pt}(\mathrm{U}-\mathrm{Nl})_{2}$ plus $\mathrm{Pd}(\mathrm{U}-\mathrm{O} 2)_{2}$ in

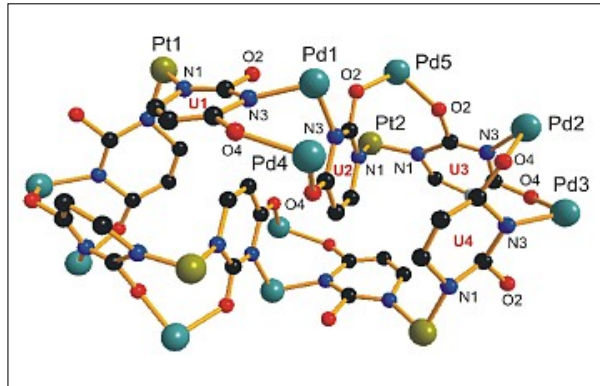

Fig. 3. Simplified view (with all en ligands deleted for simplicity) of the $\left[\left\{\text { cis- }\left(\mathrm{NH}_{3}\right)_{2} \mathrm{Pt}\right\}_{4}\{(\mathrm{en}) \mathrm{Pd}\}_{10}\right]^{12+}$ cation $^{[18]}$ head-head arrangement, $\operatorname{Pd}(\mathrm{U}-\mathrm{N} 3)_{2}$ plus $\mathrm{Pd}(\mathrm{U}-\mathrm{O} 4)_{2}$ in head-head arrangement, as well as $\mathrm{Pd}(\mathrm{U}-\mathrm{N} 3, \mathrm{O} 4)$ and $\mathrm{Pd}(\mathrm{U}-\mathrm{O} 4, \mathrm{N3})$ in head-tail fashion.

These findings strongly suggest that it is likely that cis- $\left(\mathrm{NH}_{3}\right)_{2} \mathrm{Pt}(\mathrm{II})$ and (en) $\mathrm{Pt}$ (II) alone likewise form larger ring structures, adopting the very same principles as the mixed $\mathrm{Pt}_{\mathrm{x}}, \mathrm{Pd}_{\mathrm{y}}$ compounds. Undoubtedly formation of the various rings takes place from shorter linear fragments. On the other hand ring-opening reactions can lead to open chains. With (DACH)Pd(II) (DACH $=1,2$-diaminocyclohexane) and 4,6-dimethyl-2-hydroxy-pyrimidine as bridging ligands a clean conversion of the metallacalix[6]arene to the metallcalix[4] arene has been observed upon warming. ${ }^{20]}$ With $\mathrm{Pt}(\mathrm{II})$ similar reactions may be expected to be more slowly and/or less efficient. However, sites containing head-tail arranged $\mathrm{Pt}_{2}$ units within a ring system may be considered hotspots for ring-opening and at the same time for ring-closure reactions due to the expected decreased strengths of $\mathrm{M}-\mathrm{O}$ as compared to $\mathrm{M}-\mathrm{N}$ (ring) bonds (Scheme).

Metal (Pt or Pd) entities exclusively bonded to exocyclic oxygen atoms are inherently more labile than those bonded to ring nitrogen sites. However, even



Scheme.
$\mathrm{Pt}-\mathrm{N}$ (nucleobase) bonds are subject to cleavage at low $\mathrm{pH}$.

\section{Cyclic Structures with N(1)- Substituted Pym Bases}

$\mathrm{N}(1)$-substituted pym bases (uridine, 1-methyluracil, 1-methylthymine, 1-methylcytosine) likewise form 'Blues', but these ligands have only a single ring nitrogen atom $(\mathrm{N}(3))$ available for metal coordination. It has numerously been demonstrated that in addition to $\mathrm{N}(3)$ also exocyclic sites $(\mathrm{O}(4) ; \mathrm{O}(2) ; \mathrm{N}(4) \mathrm{H})$ are utilized in metal binding, occasionally even $\mathrm{C}(5){ }^{[21]}$ As to cyclic structures, in the majority of cases, only the smallest representative, the head-tail and/or head-head dimer is observed with cis-a ${ }_{2} \mathrm{Pt}(\mathrm{II})$. Head-head dimers readily stack and can be oxidized to the tetrameric $\operatorname{Pt}(2.25)$ species (see above). In principle, larger ring systems are feasible as well, provided the two Pt centers at the N(3) and $\mathrm{X}(4)$ sites $(\mathrm{X}=\mathrm{O}$ or $\mathrm{NH})$ are mutually anti. However, only in the case of 1-methylcytosine have representative examples for trimeric $\mathrm{Pt}(\mathrm{II})^{[22]}$ and $\mathrm{Pd}(\mathrm{II})^{[23]}$ species been characterized.

\section{'Blues' - Not only Derived from cis- $\left(\mathrm{NH}_{3}\right)_{2} \mathrm{Pt}^{\prime \prime}$}

Mixed-valence states of Pt appear to be particularly easily achieved in cases where non-bulky ligands permit short Pt•••Pt contacts via the $\mathrm{d}_{\mathrm{z}^{2}}$ orbitals of Pt. $\mathrm{NH}_{3}$ ligands, as present in cis- $\left(\mathrm{NH}_{3}\right)_{2} \mathrm{Pt}$ II are therefore highly suitable for this purpose (see above). However, even the (en) $\mathrm{Pt}^{\mathrm{II}}$ moiety does permit formation of a $\mathrm{Pt}(2.25)$ 'Blue', as demonstrated in the case of $\alpha$-pyridone. ${ }^{24]}$ The assumption that only $\mathrm{Pt}-\mathrm{Pt}$ stacking interactions along at least three or four, or preferably more Pt centers leads to 'Blues' is misleading, in that even triangular $\mathrm{Pt}$ complexes, upon oxidation to $\mathrm{Pt}^{\mathrm{III}} \mathrm{P}^{\mathrm{III}} \mathrm{Pt}$ mixed-valent species, can exhibit a deep blue color. ${ }^{[25]}$

\section{DNA Binding of the 'Pt Pyrimidine Blues'}

'Pt Pyrimidine Blues' are useful staining reagents for cells in electron microscopy. ${ }^{[5]}$ The uptake of these compounds by cells incubated in solutions of the 'Blues' is so efficient, that after washing, the cells adopt a blue color. It is widely believed that the 'Blues' preferentially interact with nucleic acids. Thus, under in vitro conditions and at low ionic strength, DNA becomes rapidly precipitated as dark blue fibers. $\mathrm{Re}$ sults on the interactions of 'Pt Uracil Blue' with DNA are not fully conclusive, how- 
ever. ${ }^{[26-28]}$ It is beyond doubt that given the polycationic nature of the 'Blues', there is a strong component of non-covalent (noncoordinate) bonding with the polyanionic nucleic acids, which is dependent on ionic strength. In addition, and upon longer incubation times, there appears to be also the possibility of direct coordination of Pt species to DNA, which is reversed in part by excess cyanide. ${ }^{[27]}$ The fact that uracil ligands do not become associated with DNA in this second process, as demonstrated by the use of radioactive $\left[{ }^{14} \mathrm{C}\right]$ uracil labelled 'Pt Uracil Blue', ${ }^{[27]}$ strongly suggests that either unreacted hydrolysis products of Cisplatin present in the 'Blues' or the release of uracil-free $\mathrm{Pt}$ fragments (e.g. of cis- $\left(\mathrm{NH}_{3}\right)_{2} \mathrm{Pt}{ }^{\mathrm{II}}$ from head-head dinuclear entities) are responsible for this process.

\section{Metallacalix[4]arenes and DNA}

The questions surrounding the nature and sequence of reactions occurring between 'Pt Pyrimidine Blues' and DNA mentioned above make it desirable to study the interactions between DNA and well-characterized oligomeric Pt-pyrimidine complexes that potentially represent components of the 'Blues'. A recent study on the effects of a series of platinacalix[4]arenes derived from (en) $\mathrm{Pt}^{\mathrm{II}}$ and 2-hydroxy-5-X-pyrimidine (X $=\mathrm{Cl}, \mathrm{Br}, \mathrm{I})$ on calf thymus DNA, performed by Galindo et al.,[29] is highly instructive. As demonstrated by a variety of spectroscopic techniques and also by atomic force microscopy (AFM), the effects of these robust cationic complexes on DNA conformation are concentration dependent. While at low ratios of $\mathrm{r}=\left[\mathrm{Pt}_{4}\right]^{4+}$ :DNA the DNA undergoes coiling, causing a significant reduction in DNA length, at high $r$ values the DNA forms long, stiff rods with the possibility of aggregation into higher order DNA structures. These observations add to reports by Hannon et al. ${ }^{[30]}$ on remarkable outer-sphere interactions of supramolecular triple helicates ('molecular cylinders') with palindromic DNA sequences.

\section{Summary}

While the paramagnetism of 'Platinum Blues' is reasonably well understood and the dimer-stacking motif as a possible feature of the 'Blues' is established with $\alpha$-pyridone and 1-methyluracil ligands, coordination and connectivity patterns of unsubstituted pyrimidine ligands (uracil, thymine, cytosine) and possible interconversion mechanisms in these compounds are still poorly understood. The 'trick' of applying fast reacting cis-diamine-palladium(II) species as a 'glue' between fully characterized cis-diammineplatinum(II) complexes of these nucleobases has led to a substantial clarification of potential connectivity patterns in multinuclear complexes. As outlined above and previously reported, ${ }^{[12-14]}$ we have shown that $c i s-\mathrm{a}_{2} \mathrm{M}$ (II) $(\mathrm{M}=\mathrm{Pt}$ or $\mathrm{Pd})$ complexes, apart from binding the uracil nucleobase through either $\mathrm{N}(1)$ or $\mathrm{N}(3)$ and, in cyclic complexes, through both $\mathrm{N}(1)$ and $\mathrm{N}(3)$, the following combinations are possible: $\mathrm{N}(1) / \mathrm{N}(1), \mathrm{N}(3) / \mathrm{N}(3), \mathrm{N}(3) / \mathrm{O}(4)$ (usually doubled to give head-tail $\mathrm{M}_{2}$ species), as well as $\mathrm{O}(4) / \mathrm{O}(4), \mathrm{O}(2) / \mathrm{O}(2)$, $\mathrm{O}(4) / \mathrm{O}(2)$ (usually in conjunction with $\mathrm{N}(3) / \mathrm{N}(3), \mathrm{N}(1) / \mathrm{N}(1)$ and $\mathrm{N}(1) / \mathrm{N}(3)$, respectively, to give head-head $\mathrm{M}_{2}$ species). In larger aggregates, several of these binding motifs can exist simultaneously. Not all of these binding modes display comparable thermodynamic stabilities: Thus, $\mathrm{M}-\mathrm{O}$ bonds are weaker than $\mathrm{M}-\mathrm{N}$ bonds and can be subject to dissociation under a variety of conditions, but even $\mathrm{M}-\mathrm{N}$ bonds can be cleaved under acidic conditions, and possibly also at high $\mathrm{pH}$. It is to be assumed that all the binding modes seen by $\mathrm{Pd}(\mathrm{II})$ are possible for $\mathrm{Pt}(\mathrm{II})$ as well. We are aware that the use of $\mathrm{Pd}$ (II) and in particular the use of 2,2'-bpy as the diamine entity has a dramatic influence on the possibility of generating a 'Blue' by simple oxidation through air. In fact, it is highly unlikely to be realized, and none of the mixed multinuclear Pt,Pd complexes characterized by us with unsubstituted uracil and cytosine ligands are blue in color.

\section{Acknowledgements}

Support by the Deutsche Forschungsgemeinschaft, the Fonds der Chemischen Industrie, and the University of Dortmund is gratefully acknowledged.

Received: July 27, 2007

[1] E. Wong, C. M. Giandomenico, Chem. Rev. 1999, 99, 2451.

[2] N. Farrell, S. Spinelli, in 'Uses of Inorganic Chemistry in Medicine', Ed. N. P. Farrell, Roy. Soc. Chem., Cambridge, 1999 , p. 124.

[3] J. P. Davidson, P. J. Faber, R. G. Fischer, Jr., S. Mansy, H. J. Peresie, B. Rosenberg, L. VanCamp, Cancer Chemother. Rep. Part 1 1975, 59, 287.

[4] B. Lippert, in 'Cisplatin-Chemistry and Biochemistry of Leading Anticancer Drugs', Ed. B. Lippert, VHCA Zürich and Wiley-VCH, Weinheim, 1999, p. 379.

[5] S. K. Aggarwal, R. W. Wagner, P. K. McAllister, B. Rosenberg, Proc. Nat. Acad. Sci. USA 1975, 72, 928.

[6] B. Lippert, J. Clin. Hemat. Oncol. 1977, 7, 26.

[7] J. K. Barton, H. N. Rabinowitz, D. J. Szalda, S. J. Lippard, J. Am. Chem. Soc. 1977, 99, 2827.

[8] P. K. Mascharak, I. D. Williams, S. J. Lippard, J. Am. Chem. Soc. 1984, 106, 6428.
[9] K. Matsumoto, K. Sakai, Adv. Inorg. Chem. 2000, 49, 375.

[10] K. Sakai, M. Tadeshita, Y. Tanaka, T. Ue, M. Yanagisawa, M. Kosaka, T. Tsubomura, M. Ato, T. Nakano, J. Am. Chem. Soc. 1998, $120,11353$.

[11] B. Lippert, Coord. Chem. Rev. 1999, 182, 263.

[12] H. Rauter, E. C. Hillgeris, B. Lippert, $J$. Chem. Soc., Chem. Commun. 1992, 1385.

[13] H. Rauter, E. C. Hillgeris, A. Erxleben, B. Lippert, J. Am. Chem. Soc. 1994, 116, 616.

[14] H. Rauter, I. Mutikainen, M. Blomberg, C. J. L. Lock, P. Amo-Ochoa, E. Freisinger, L. Randaccio, E. Zangrando, E. Chiarparin, B. Lippert, Angew. Chem., Int. Ed. Engl. 1997, 36, 1296.

[15] J. A. R. Navarro, E. Barea, M. A. Galindo, J. M. Salas, M. Angustias Romero, M. Quirós, N. Masciocchi, S. Galli, A. Sironi, B. Lippert, J. Solid. State Chem. 2005 , 178, 2436 and refs. cited.

[16] J. A. R. Navarro, E. Freisinger, B. Lippert, Inorg. Chem. 2000, 39, 2301.

[17] W. Micklitz, G. Müller, B. Huber, J. Riede, F. Rashwan, J. Heinze, B. Lippert, J. Am. Chem. Soc. 1998, 110, 7084.

[18] E. Gil Bardají, B. Lippert, unpublished results.

[19] E. Gil Bardají, E. Freisinger, B. Costisella, C. A. Schalley, W. Brüning, M. Sabat, B. Lippert, Chem. Eur. J. 2007, 13, 6019.

[20] E. Barea, J. A. R. Navarro, J. M. Salas, M. Quirós, M. Willermann, B. Lippert, Chem. Eur. J. 2003, 9, 4414.

[21] B. Lippert, Prog. Inorg. Chem. 1989, 37, 1.

[22] L. Schenetti, G. Bandoli, A. Dolmella, G. Trovó, B. Longato, Inorg. Chem. 1994, 33, 3169.

[23] W.-Z. Shen, D. Gupta, B. Lippert, Inorg. Chem. 2005, 44, 8249.

[24] J. H. Burness, M. J. Bandurski, L. J. Passman, B. Rosenberg, J. Clin. Hemat. Oncol. 1977, 7, 508.

[25] W. Bauer, S. L. Gonias, S. K. Kam, K. C. Wu, S. J. Lippard, Biochemistry 1978, 17, 1060.

[26] M. S. Herrmann, A. D. Cardin, W. D. Behnke, J. R. Durig, Biochem. Pharmacol. 1978, 27, 1571.

[27] V. O'Halloran, M. M. Roberts, S. J. Lippard, J. Am. Chem. Soc. 1984, 106, 6427.

[28] Umakoshi, T. Kojima, Y. H. Kim, M. Onishi, Y. Nakao, S. Sakaki, Chem. Eur. J. 2006, 12, 6521 .

[29] M. Galindo, D. Olea, M. A. Romero, J. Gómez, P. del Castillo, M. J. Herrmann, A. Rodger, F. Zamora, J. A. R. Navarro, Chem. Eur. J. 2007, 13, 5075.

[30] A. Olesky, A. G. Blanco, R. Boer, I. Usón, J. Aymaní, A. Rodger, M. J. Hannon, M. Coll, Angew. Chem., Int. Ed. 2006, 45, 1227. 